INEEL/EXT-01-00306

February 2001

\title{
Tritium Inventory in ARIES-AT
}

G. R. Longhurst

BECHTEL BWXT I DAHO, L LC 
INEEL/EXT-01-00306

\title{
Tritium Inventory in ARIES-AT
}

\author{
G. R. Longhurst
}

Published February 2001

\section{Idaho National Engineering and Environmental Laboratory Nuclear Engineering Design and Research Department Idaho Falls, Idaho 83415}

\author{
Prepared for the \\ U.S. Department of Energy \\ Assistant Secretary for Science \\ Under DOE Idaho Operations Office \\ Contract DE-AC07-99ID13727
}




\begin{abstract}
This report documents an investigation into the tritium inventory expected in the ARIES-AT fusion reactor. ARIES-AT features silicon carbide fibers in a silicon carbide matrix as its primary construction. It uses the same fusion power core as the previous ARIES-RS. Based on experimental results of several researchers, consideration was given to swelling, sputtering, film coatings, erosion, and implantation. Estimates were made of tritium inventory using the TMAP4 code. About $700 \mathrm{~g}$ of tritium may be expected in the machine, two thirds of which would reside in the first wall. Under assumed accident conditions that involve firs wall temperatures up to $1000^{\circ} \mathrm{C}$, evolution of retained tritium may be expected to vary from 0.8 to nearly 40 percent depending on the temperature of the first wall.
\end{abstract}





\section{CONTENTS}

OBJECTIVE 1

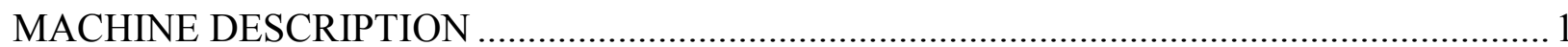

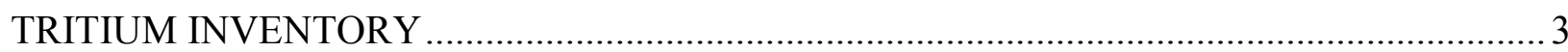

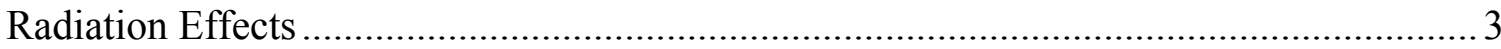

Plasma Particle Loading in ARIES-AT …........................................................... 5

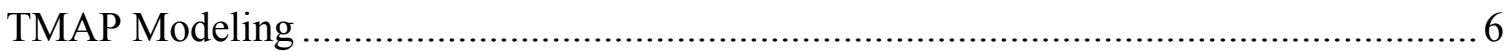

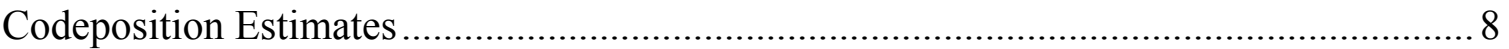

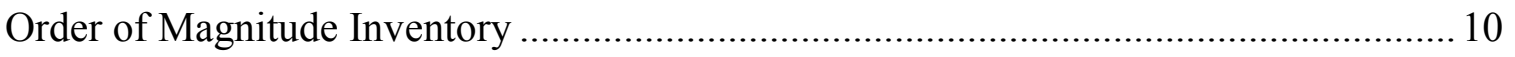

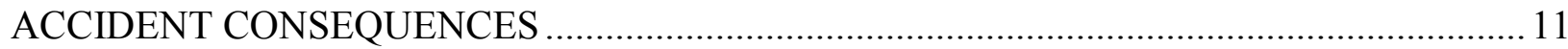

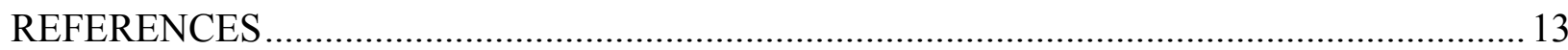

Appendix A-Tmap Input Files And Results ............................................................ 15

\section{FIGURES}

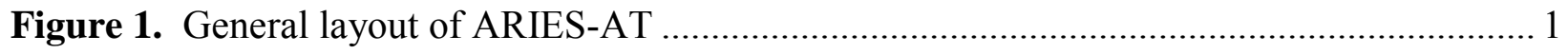

Figure 2. ARIES-AT outboard first wall and blanket. .................................................. 2

Figure 3. Outboard first wall/blanket cross section....................................................... 2

Figure 4. ARIES-AT first wall configuration details......................................................... 2

Figure 5. ARIES-AT divertor coolant flow paths. .............................................................. 2

Figure 6. Cross section of ITER plasma chamber showing various regions referred to in Table 1 for plasma particle fluxes

Figure 7. Experimental data from Doyle et al. for the $\mathrm{H}: \mathrm{C}$ ratio as a function of formation temperature, and a functional fit to those data 
Figure 8. Erosion yields as a function of incident beam energy at $45^{\circ}$ incidence from Mohri et al. Also shown are normal-incidence data for $\mathrm{H}^{+}$bombardment of $\mathrm{SiC}$ from Roth et al. The line through the $\mathrm{Ar}^{+}$data is a least-squares linear fit........................................ 10

Figure 9. Release of tritium following three years of operation at $10^{21} \mathrm{DT} / \mathrm{m}^{2} . \mathrm{s}$ and assuming $\mathrm{SiC}$ structure is held at 500,750 , and $1,000^{\circ} \mathrm{C}$ following an accident. Release fractions after one year are $0.8,6.6$, and 39.7 percent, respectively

\section{TABLES}

Table 1. Plasma particle loads estimated for ITER and thought to be representative of those that may be seen in ARIES-AT .

Table 2. Order-of-magnitude estimate of tritium inventory in ARIES-AT after 3 years of operation. Figures could be low or high by a factor of 2 . 


\section{Tritium Inventory in ARIES-AT \\ OBJECTIVE}

The objective of this study is to estimate tritium inventory in ARIES-AT and to evaluate safety consequences associated with that inventory. The approach makes use of available design information, estimates of surface particle fluxes and energies, and the TMAP4 code to assess the buildup of tritium in the structure and, to the extent possible, in the cooling system. Then some accident scenarios will be investigated to evaluate tendencies for tritium release.

\section{MACHINE DESCRIPTION}

As presently configured, ARIES-AT makes use of essentially the same power core configuration as the previous ARIES-RS, but the structure is different. Figure 1 shows the general layout of the machine. The plasma has a double-null divertor configuration and a net plasma fusion power of $2170 \mathrm{MW}$.

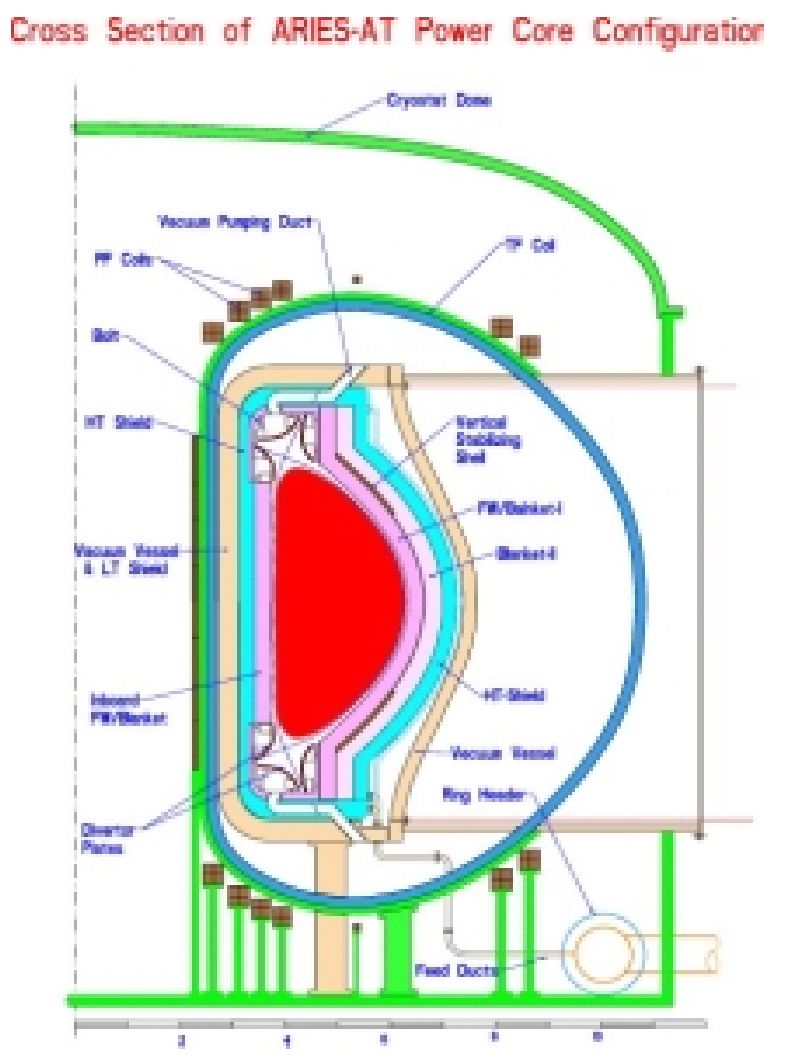

Figure 1. General layout of ARIES-AT
Key design parameters significant to tritium inventory are the construction of the first wall-blanket (FW/B) and divertor sections, the coolant flows and the plasma particle fluxes to the adjacent structures. Figure 2 shows the general structure of the segments making up the first wallblanket, and Figures 3 and 4 show additional details. Figure 5 shows some detail for the divertor region.

The plasma-facing structure of ARIES-AT is of $\mathrm{SiC}_{\mathrm{f}} / \mathrm{SiC}$ (silicon carbide fibers woven and embedded in a silicon carbide matrix). The structures are rather thin but stiff, essentially concentric shells connected by thin webs. The divertor plates are of tungsten. 


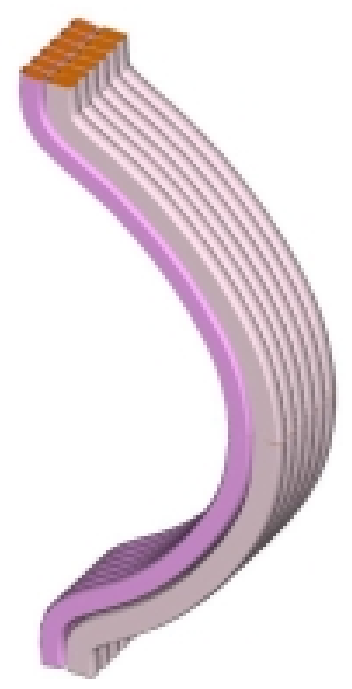

Figure 2. ARIES-AT outboard first wall and blanket.

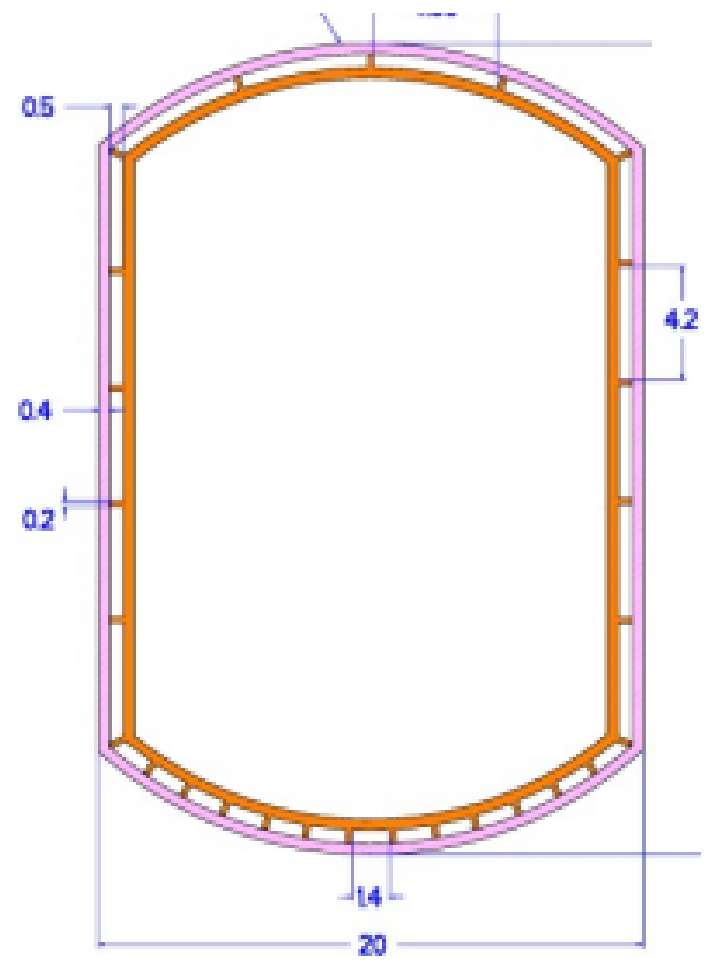

Figure 4. ARIES-AT first wall configuration details.

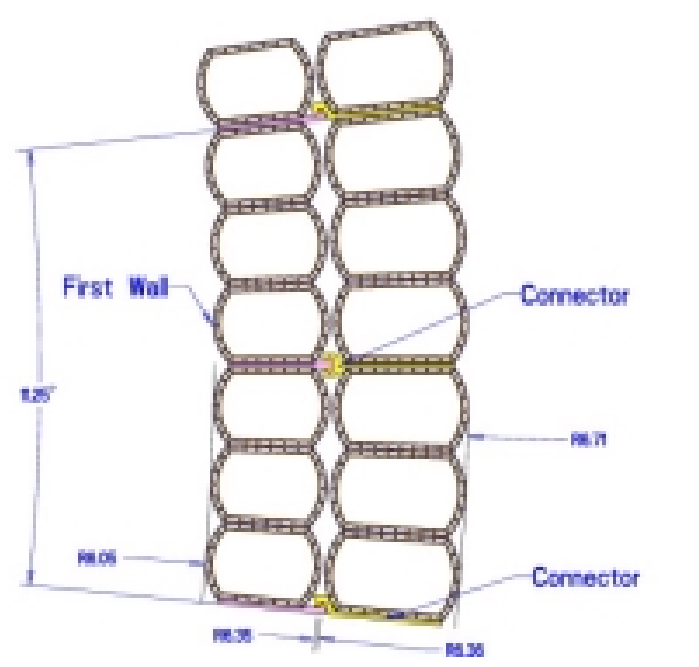

Figure 3. Outboard first wall/blanket cross section.

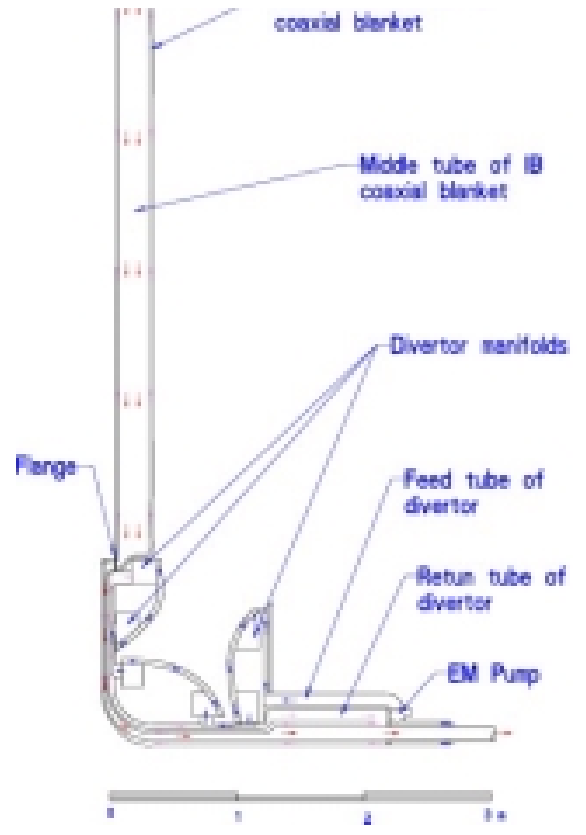

Figure 5. ARIES-AT divertor coolant flow paths. 


\section{TRITIUM INVENTORY}

\section{Radiation Effects}

The anticipated lifetime of the FW/Blanket structure is 3 years. With a nominal $14-\mathrm{MeV}$ neutron power of $1390 \mathrm{MW}$ over $430 \mathrm{~m}^{2}$ of surface area, the average neutron flux rate would be $1.4 \times 10^{18} \mathrm{n} / \mathrm{m}^{2} \mathrm{~s}$. If there were 300 effective full power days per year, and there are 1.16 $\mathrm{dpa} / 10^{25} \mathrm{n} / \mathrm{m}^{2}$, then FW structures may be expected to have about $12.5 \mathrm{dpa}$ at the end of their lifetime. That may generate significant changes in the material. Here we consider what some of those changes may be.

ARIES-AT will operate at elevated FW temperatures. The ARIES-AT requirement is that the $\mathrm{SiC}$ operate at less than $1000^{\circ} \mathrm{C}$. Present estimates are that the $\mathrm{FW}$ will operate with a maximum surface heat flux to the wall of $0.7 \mathrm{MW} / \mathrm{m}^{2}$ with an average surface heat flux of $0.5 \mathrm{MW} / \mathrm{m}^{2}\left[{ }^{1}\right]$. Thermal conductivity for the $\mathrm{SiC}_{\mathrm{f}} / \mathrm{SiC}$ material varies with the method of production, density,

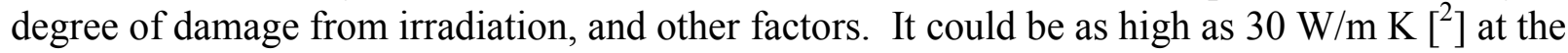
working temperature, but a more realistic value may be $20 \mathrm{~W} / \mathrm{m} \mathrm{K}$ [1]. The design-team calculated temperature distribution in the $\mathrm{FW}$ structure is peaked at about $1000^{\circ} \mathrm{C}$ near the midplane, falling off to about $700^{\circ} \mathrm{C}$ at the bottom end and to about $850^{\circ} \mathrm{C}$ at the top.

A further consideration is the potential for annealing of defects and recrystallization of the $\mathrm{SiC}$ at elevated temperatures. Kawatsura et al. ${ }^{3}$ have found that the critical dose of implanted ions for amorphization of the $\mathrm{SiC}$ crystal depends on the mass of the implanting ion and on temperature. They found that at room temperature, the critical dose best-fit line varies according to

$\Gamma_{\text {crit }}\left(\frac{\text { atom }}{m^{2}}=2.2 \times 10^{20} \mathrm{Z}^{-1.3}\right.$

meaning that for $\mathrm{H}(\mathrm{Z}=1)$, the critical dose is $2.2 \times 10^{20}$ atom $/ \mathrm{m}^{2}$. Kawatsura et al. cite data from Spitznagel et al. [ ${ }^{4}$ ] giving the critical flux for $\mathrm{H}$ into $\mathrm{SiC}$ as $9 \times 10^{20}$ atom $/ \mathrm{m}^{2}$. Presumably, the Spitznagel data are for ambient-temperature implantation.

In annealing investigations, Kawatsura et al. ${ }^{3}$ observed a $25-\mathrm{nm} \mathrm{SiO}_{2}$ layer on an $\alpha-\mathrm{SiC}$ crystal surface after annealing for $2 \mathrm{~h}$ in argon at $1200^{\circ} \mathrm{C}$. Such films may retard sublimation of $\mathrm{SiC}$ at elevated temperatures, and they may themselves sublime. ${ }^{5}$ Oxygen incorporated in the fibers may also come out as $\mathrm{CO}^{6}$

No change in the crystal structure (amorphization) was seen after a $2-\mathrm{h}$ anneal at $1000^{\circ} \mathrm{C}$. After annealing at $1500^{\circ} \mathrm{C}$, however, Kawatsura et al. observed a defect layer with a very high concentration of the implanted $\mathrm{Ni}$ atoms at the 540-nm implantation depth. For ARIES-AT, the implantation depth is expected to be in the range of a few tens of angstroms. It is not clear to what extent the damage region would develop for such shallow implantation depths. 
Neutron irradiation produces linear swelling in SiC. Scholz ${ }^{7}$ quoting Price ${ }^{8}$ indicates that swelling saturates at about $0.5 \mathrm{dpa}$, and the amount of swelling at saturation varies with temperature according to

$$
\frac{\Delta L}{L}=0.011-1.1 \times 10^{-5} T\left({ }^{\circ} \mathrm{C}\right)
$$

The data indicate that for an operating temperature of $1,000^{\circ} \mathrm{C}$, one may expect linear swelling to saturate at about 0.1 percent, though for regions where the temperature is lower, the swelling may reach 1 percent or so.

Swelling may have an effect on tritium retention, particularly if the increased volume is partially filled with tritium atoms or molecules. Saito et al. ${ }^{9}$ found that implantation of He at $3 \mathrm{MeV}$ to about 10,000 appm produced bubbles that were observable after annealing at 1,673 $\mathrm{K}$, but not before annealing. These bubbles appeared in the SiC matrix only and not in the SiC fibers. Scholz et al. ${ }^{10}$ injected He to 2,500 appm in SiC composites at $1175 \mathrm{~K}$. They observed swelling of the matrix but contraction of the fibers. They concluded that the presence of the He may suppress annealing of structural damage at that temperature. Similar results were seen by Frias Rebelo et al. ${ }^{11}$ where the effect was seen after both neutron and helium ion exposure. Bacon et al. ${ }^{12}$ reported gas-driven flaking when $\mathrm{SiC}$ at $700^{\circ} \mathrm{C}$ was bombarded with $40-\mathrm{keV}$ helium ions to a dose of $5 \times 10^{21}$ ion $/ \mathrm{m}^{2}$. Flake thickness corresponded to the implantation depth, and its existence was thought to correspond to the absence of amorphous structure at elevated temperatures.

Another issue of concern is the potential for composition change at the surface due to sputtering actions. Carbon and silicon atoms are expected to be sputtered individually. In the presence of hydrogen, carbon sputtered from a carbon substrate is known to redeposit as amorphous hydrocarbon $\mathrm{CH}_{\mathrm{x}}$, where $\mathrm{x}$ is in the range of $0.1-0.4$, the value depending on temperature, hydrogen partial pressure, and possibly other factors. Silicon is also believed to form hydrogenic films. It is not known to what extent these processes would be applicable in ARIES-AT. ${ }^{13}$ Data that may be relevant are from Xu et al. ${ }^{14}$ who observed that vapor deposition of $\mathrm{SiC}$ from methyltrichlorosilane in a hydrogen gas carrier at temperatures ranging from 1000 to $1300{ }^{\circ} \mathrm{C}$ resulted in the formation of pure, mostly $\beta$ phase $\mathrm{SiC}$ crystallites. Neither free silicon nor free carbon was found. The $\mathrm{SiC}$ was poorly crystallized and very fine $(\sim 10 \mathrm{~nm})$. As the deposition temperatures decreased, the crystallite size became smaller. They also observed the formation of a thin (24-nm) $\mathrm{SiO}_{2}$ film from system residual oxygen. That film was readily sputtered away under the Auger analysis beam in about 10 minutes. Lower surface temperatures may favor amorphous hydrogenic film formation whereas at higher temperatures it may not form.

Mohri et al. ${ }^{15}$ measured sputtering rates of $\mathrm{SiC}$ bombarded with $\mathrm{H}^{+}, \mathrm{D}^{+}$, and $\mathrm{Ar}^{+}$ions at energies of $5-13 \mathrm{keV}$ and various incidence angles. They found erosion yields for $\mathrm{H}^{+}$incident at an angle of $45^{\circ}$ peaked at about $8 \mathrm{keV}$ with a value of about 0.03 atoms/ion. Angular dependence showed the greatest yields at angles from $50-80^{\circ}$. They also saw evidence for the formation of hydrocarbons and silicon hydrides during sputtering with $\mathrm{H}^{+}$. Sputtering yields for $\mathrm{D}^{+}$were approximately a factor of 2 higher than for $\mathrm{H}^{+}$, as may be expected. They observed that 
sputter yields are greater for fully dense material, such as they used, than for porous material. This is apparently due to the capacity of the porosity to port off implanted gas atoms that in fully dense material cause blistering and flaking.

These considerations lead to the following summary of possibilities for modeling, regarding the state of the $\mathrm{SiC}_{\mathrm{f}} / \mathrm{SiC}$ in the ARIES-AT environment.

- There may be a thin $\mathrm{SiO}_{2}$ film on the $\mathrm{SiC}$ surface, but more likely, it will be sputtered clean. Oxide films have been observed on many materials in similar situations. There may well be a competition between film formation and film erosion due to the sputtering effect of the plasma that will depend on temperature and on the oxygen impurity content of the plasma. If such films form and inhibit return of implanted hydrogen isotope atoms to the plasma, continued implantation will lead to exceptionally high concentrations of implanted atoms at the implantation depth that will probably induce flaking.

- It is also possible that there will be thin films of amorphous $\mathrm{C}: \mathrm{H}$ and $\mathrm{Si}: \mathrm{H}$. Hydrogenic films are expected to be more permeable to hydrogen isotopes than $\mathrm{SiC}$ will be. Therefore, if any such films grow to thicknesses exceeding the implantation depth, implantation burden to the SiC substrate would stop.

- Neutron irradiation may generate trapping sites in the SiC. Swelling should saturate within about 4 percent of the FW lifetime, so it may be possible to simply model traps as constant at about 1,000-10,000 appm. Trap strength is not known, but it may be about $2 \mathrm{eV}$, the molecular formation free energy per atom. Traps would be more or less uniformly distributed throughout the thickness of the wall.

- The tendency of the matrix $\mathrm{SiC}$ to swell while the fibers contract under irradiation has the potential for partial debonding of the matrix from the fibers. If this happens, there may be microchannels for release of tritium and other gases along the interface between the matrix and the fibers. If that is true, then the mean diffusion distance for release of implanted tritium would be only about the fiber diameter or about $10 \mu \mathrm{m}$. On the other hand, tritium coming from an effective partial pressure at the surface of the SiC could migrate through the structure much faster. The effects of these channels could be modeled by using a higher diffusivity.

\section{Plasma Particle Loading in ARIES-AT}

There have been few studies of plasma edge conditions and particle fluxes to surfaces for the ARIES-AT design. Obviously, the device is a tokamak, and the plasma should exhibit conditions similar to those of any other large power tokamak concept studied by the community thus far. However, little work has been done yet specifically to address plasma properties, especially edge plasma issues, for the ARIES-AT. One of the greatest areas of uncertainty is the degree of detachment of the plasma from the divertor. That will have a profound effect on the particle flux density and particle energies impacting the divertor plate. 
Plasma conditions are believed to be comparable to those postulated for the International Thermonuclear Experimental Reactor (ITER) ${ }^{13}$. Those conditions are summarized in Table 1. The various areas referred to in Table 1 are shown schematically in Figure 6.

Table 1. Plasma particle loads estimated for ITER and thought to be representative of those that may be seen in ARIES-AT. ${ }^{16}$

\begin{tabular}{|c|c|c|c|}
\hline Region & $\begin{array}{l}\text { Particle Flux Density } \\
\qquad\left(10^{20} \mathrm{DT} / \mathrm{m}^{2} \mathrm{~s}\right)\end{array}$ & $\begin{array}{c}\text { Particle } \\
\text { Characteristic } \\
\text { Energy (eV) }\end{array}$ & $\begin{array}{c}\text { Fast Neutron Flux } \\
\text { Density } \\
\left(10^{18} \mathbf{n} / \mathbf{m}^{2} \mathbf{s}\right)\end{array}$ \\
\hline First Wall & $0.1-1$ & $100-500$ & $1.9-2.3$ \\
\hline Limiter & $10-100$ & $100-500$ & 2.3 \\
\hline Upper Baffle & $0.1-1$ & $100-500$ & 2 \\
\hline Lower Baffle & $1-10$ & 100 & 1.1 \\
\hline Lower Target & $<10,000$ & $<5$ & $0.4-0.6$ \\
\hline Divertor Sidewall & $1-10$ & $5-100$ & $0.6-1.1$ \\
\hline Dome & $1-10$ & $5-100$ & $0.6-1.1$ \\
\hline
\end{tabular}

In addition to particle streaming into the plasma-facing surfaces, mostly as charge-exchange neutral atoms, there will be some tendency of neutral gas molecules to circulate around the structures and become incorporated into surfaces by codeposition or simple plate out. Such was seen in both TFTR and JET where inventories of tritium were high in the side surfaces of tiles and in carbonaceous flakes deposited on and near vacuum pumping port louvers. ${ }^{17,18}$

TRIM calculations suggest average implantation depths for normal incidence of $\mathrm{D} / \mathrm{T}$ in $\mathrm{SiC}$ varying from 35 angstroms at $100 \mathrm{eV}$ to 125 angstroms at $500 \mathrm{eV}$ ion energy. Straggle varies correspondingly from 20 to 60 angstroms. Those numbers don't change much if there is a 25 angstrom surface layer of $\mathrm{SiO}_{2}$.

\section{TMAP Modeling}

The recommended ${ }^{19}$ value for solubility of hydrogen isotopes in $\mathrm{SiC}$ is

$\mathrm{S}\left(\frac{\text { atom }}{\mathrm{m}^{3} \mathrm{~Pa}^{1 / 2}}\right)=2.58 \times 10^{19} \exp \left(\frac{0.61 \mathrm{eV}}{\mathrm{kT}}\right)$

while hydrogen diffusivity is 


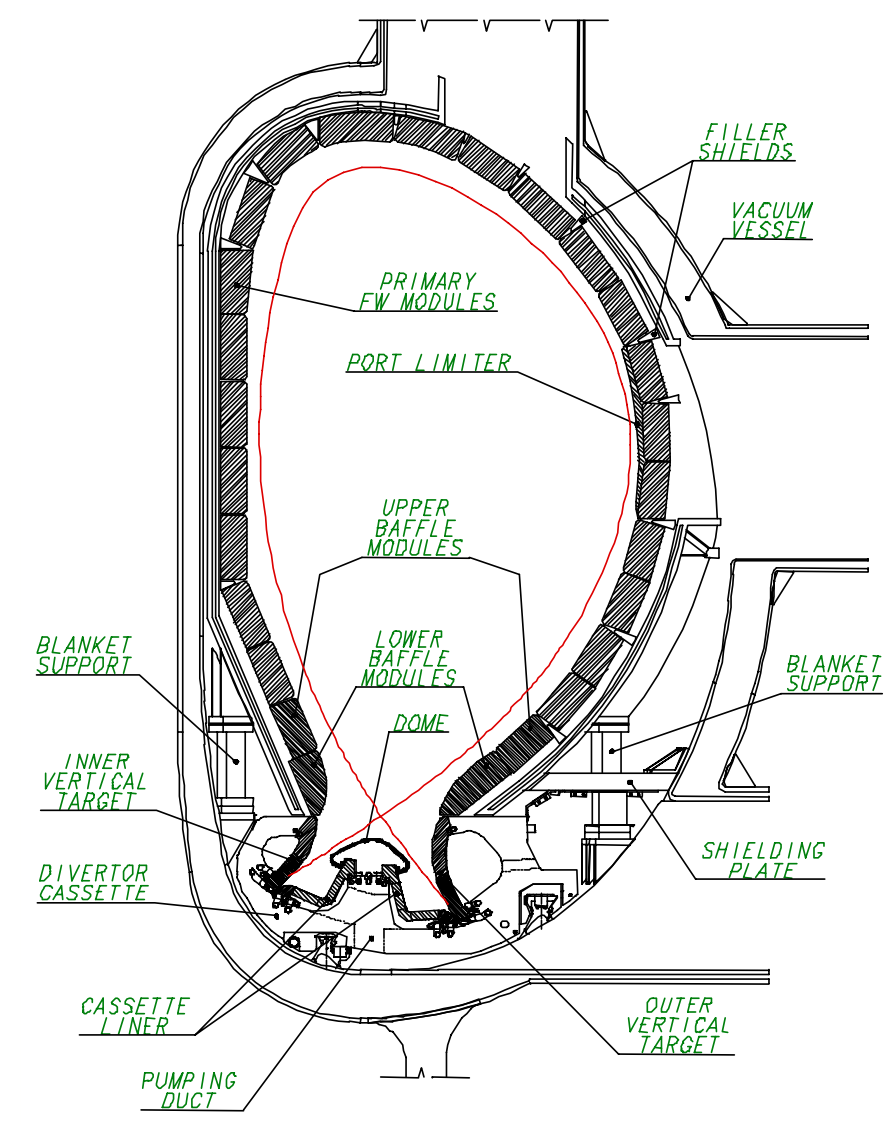

Figure 6. Cross section of ITER plasma chamber showing various regions referred to in Table 1 for plasma particle fluxes. ${ }^{16}$

$\mathrm{D}\left(\frac{\mathrm{m}^{2}}{\mathrm{~s}}\right)=9.8 \times 10^{-8} \exp \left(-\frac{1.89 \mathrm{eV}}{\mathrm{kT}}\right)$

We can explore several bounding conditions on implantation uptake for $\mathrm{SiC}$ in the first wall. One is the assumption that there is enough surface activity of hydrogen isotopes and other species, or sufficiently high porosity in the surface, that there is a zero surface concentration boundary with implantation at the nominal depth and scatter, and assume that there are no traps. A second option would assume traps at $10,000 \mathrm{ppm}$ (0.01 atom fraction) concentration and 2.1 $\mathrm{eV}$ trapping energy. This is close enough to the diffusion activation energy that it will not have much effect. A boundary where there is very little reemission (non-flow boundary) is unlikely because the extremely high loading at the implantation depth would promote blisters or flaking. Another option might be a Sieverts' law boundary condition, but estimates of gas pressures near the surfaces would be needed to render that assumption viable. Advice ${ }^{13}$ is that there have not yet been enough edge plasma studies to justify guesses on those pressures.

The TMAP4 code was used to get some quantitative estimates of tritium inventory buildup. For simplicity, the computations were conducted for deuterium alone rather than a mix of 
deuterium and tritium, but it is not significantly different than if a D/T mix were used. For this segment of the analysis, the plasma facing material is assumed to be purely $\mathrm{SiC}$ and to consist of a simple slab $4 \mathrm{~mm}$ thick. Appendix A contains several TMAP input files and selected results from that modeling.

The first or reference case used an implantation flux of $10^{21} \mathrm{D} / \mathrm{m}^{2}-\mathrm{s}$ with implantation distributed approximately as calculated by TRIM. Both upstream and downstream faces were assumed to be at the "c $=0$ " condition for diffusive boundary conditions. The inventory after three years was only about 7 percent $\left(1.75 \mathrm{~g} / \mathrm{m}^{2}\right)$ of its saturation value $\left(24.7 \mathrm{~g} / \mathrm{m}^{2}\right)$. Increasing the implantation flux by a factor of ten increased the inventory by the same factor of ten.

The second case modeled was similar to the first, but it included a temperature gradient of $200 \mathrm{~K}$ across the 4-mm thickness of the sample, beginning at the same $1,000^{\circ} \mathrm{C}$ at the implantation face as in the previous case. This gradient is probably an extreme, but it was selected to evaluate the effect. Also included in another simulation for comparison were traps at $2.1 \mathrm{eV}$ trap energy and 0.01 atom fraction concentration. The temperature gradient added almost a factor of 10 to the inventory by inhibiting diffusion through the bulk of the wall and forcing higher concentrations near the implantation zone. These reached to about half of the SiC lattice atom density in the implantation region. The traps added 1 percent to the total inventory, as may have been be predicted apriori. Again, further details are in Appendix A.

Another inventory of implanted tritium will be in the divertor plates. Because they are of tungsten, as were the divertor plates in the ITER concept studied previously, ${ }^{20,21}$ with effectively the same loading and operating conditions (at least no significant differences have been yet identified), we may be justified in simply bringing those results forward to this study. The estimated specific inventory in the $10-\mathrm{mm}$ thick tungsten sidewall divertor plates in ITER was $0.4 \mathrm{~g} / \mathrm{m}^{2}$. For a divertor area of $67.7 \mathrm{~m}^{2}$, that translates to a $27 \mathrm{~g}$ inventory in ARIES-AT. Even though particle flux densities are much higher to these components than to the first wall, the saturation effect in tungsten ${ }^{22}$ and high recycling means that these structures will not have so much tritium burden as will the $\mathrm{SiC}$ structures. This inventory was calculated to saturate in less than 0.1 years of operation.

\section{Codeposition Estimates}

Codeposition estimates are essentially wholly dependent on the rate of sputtering of carbon and silicon from the $\mathrm{SiC}$ surfaces. The carbon atoms will be reionized and redeposit in a short distance, a very few $\mathrm{cm}$, from the surface. The ionization mean free path for silicon atoms is much longer, leading to the suspicion that amorphous carbon and silicon films may form under tokamak conditions. Experience has shown that these amorphous film molecules tend to migrate to the coolest surfaces they have access to, which often is on the sides of plasma-facing structures or vacuum pumping ducts.

The hydrogen content of codeposited hydrocarbon films depends on the temperature at which they are formed. Results from Doyle ${ }^{23}$ on the hydrogen content of such films as a function of temperature are shown in Figure 7 together with a functional fit to those data. It may be seen there that if the operating temperature is up around $1,000^{\circ} \mathrm{C}$, the $\mathrm{H}: \mathrm{C}$ ratio will be low. 


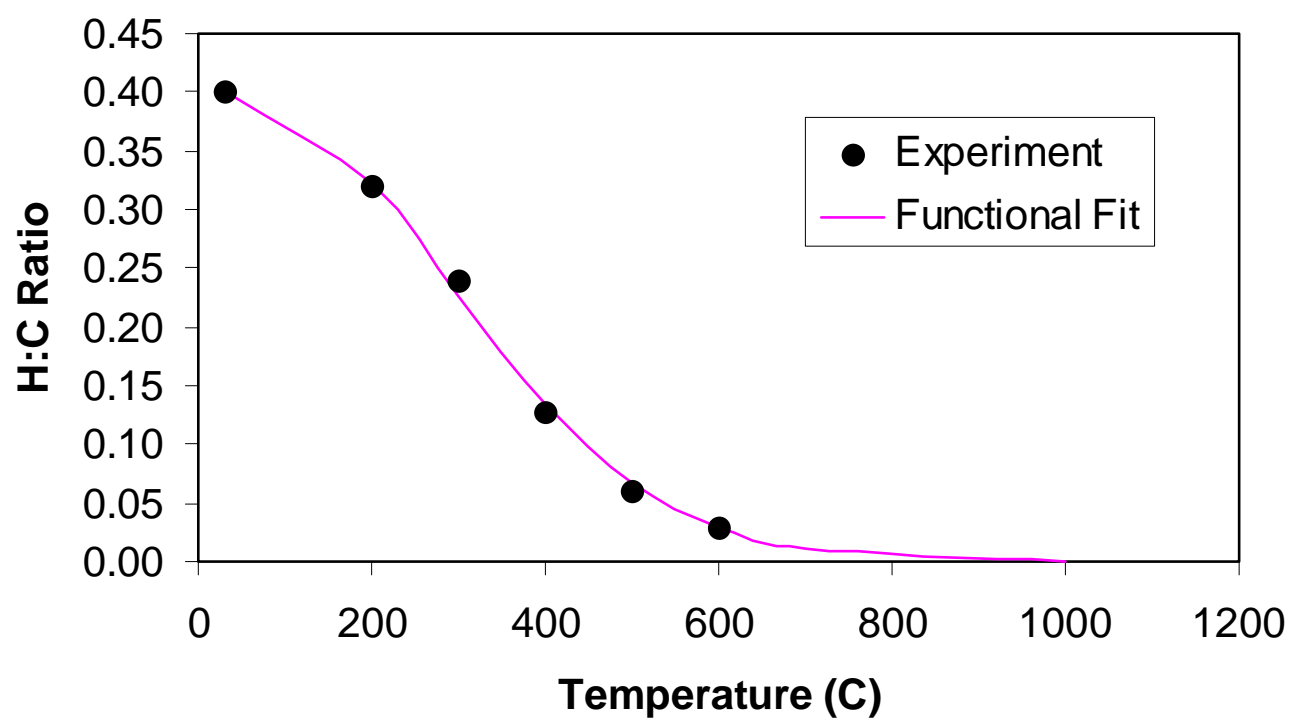

Figure 7. Experimental data from Doyle et al. ${ }^{23}$ for the $\mathrm{H}: \mathrm{C}$ ratio as a function of formation temperature, and a functional fit to those data.

The functional fit suggests it will be of order $2 \times 10^{-4}$. At $800^{\circ} \mathrm{C}$ it is about $3 \times 10^{-3}$. As noted earlier, the design-team calculated temperature distribution in the $\mathrm{FW}$ structure is peaked at about $1000^{\circ} \mathrm{C}$ near the mid-plane, falling off to about $700^{\circ} \mathrm{C}$ at the bottom end and about $850^{\circ} \mathrm{C}$ at the top. The non-linearities shown in Figure 7 imply that the greatest tritium inventory in codeposited films will be in those areas that are the coolest. For an order of magnitude estimate, suppose that the mean effective temperature of this coolest area is $700^{\circ} \mathrm{C}$ and that it represents 20 percent of the first wall area or about $60 \mathrm{~m}^{2}$. The functional fit in Figure 7 suggest a H:C ratio of 0.01 at $700^{\circ} \mathrm{C}$. If tritium constitutes half the hydrogen, then $\mathrm{T}: \mathrm{C}$ is about 0.005 at that temperature.

Figure 8 shows sputter yield data from Mohri et al ${ }^{15}$ for $\mathrm{H}^{+}, \mathrm{D}^{+}$, and $\mathrm{Ar}^{+}$bombarding $\mathrm{SiC}$. These are shown in terms of energy per $\mathrm{H}$ or Ar nucleus based on reported fractions of $\mathrm{H}_{1} \mathrm{H}_{2}{ }^{+}$, and $\mathrm{H}_{3}{ }^{+}$and the stated beam energy. For comparison, similar data by Roth et al. ${ }^{24}$ are shown. The right-most data point from Roth et al. was for less than fully dense material, while the rest of the data were for fully dense SiC. Additionally, the experiments of Roth et al. were at normal incidence whereas Mohri et al. conducted their experiments at $45^{\circ}$ incidence angle where yields should be higher. The figure suggests that sputter yield of $\mathrm{SiC}$ will be about 0.01 regardless of isotope or energy. Less than fully dense material appears to experience less sputtering because of the propensity for the voids to port away hydrogen that in fully dense material would cause micro-blistering and contribute to the erosion. There was no apparent chemical erosion of the $\mathrm{SiC}$ due to the $\mathrm{H}$ or $\mathrm{D}$ ions, whereas in graphite sputtering, chemical erosion dominates in some temperature regimes. 


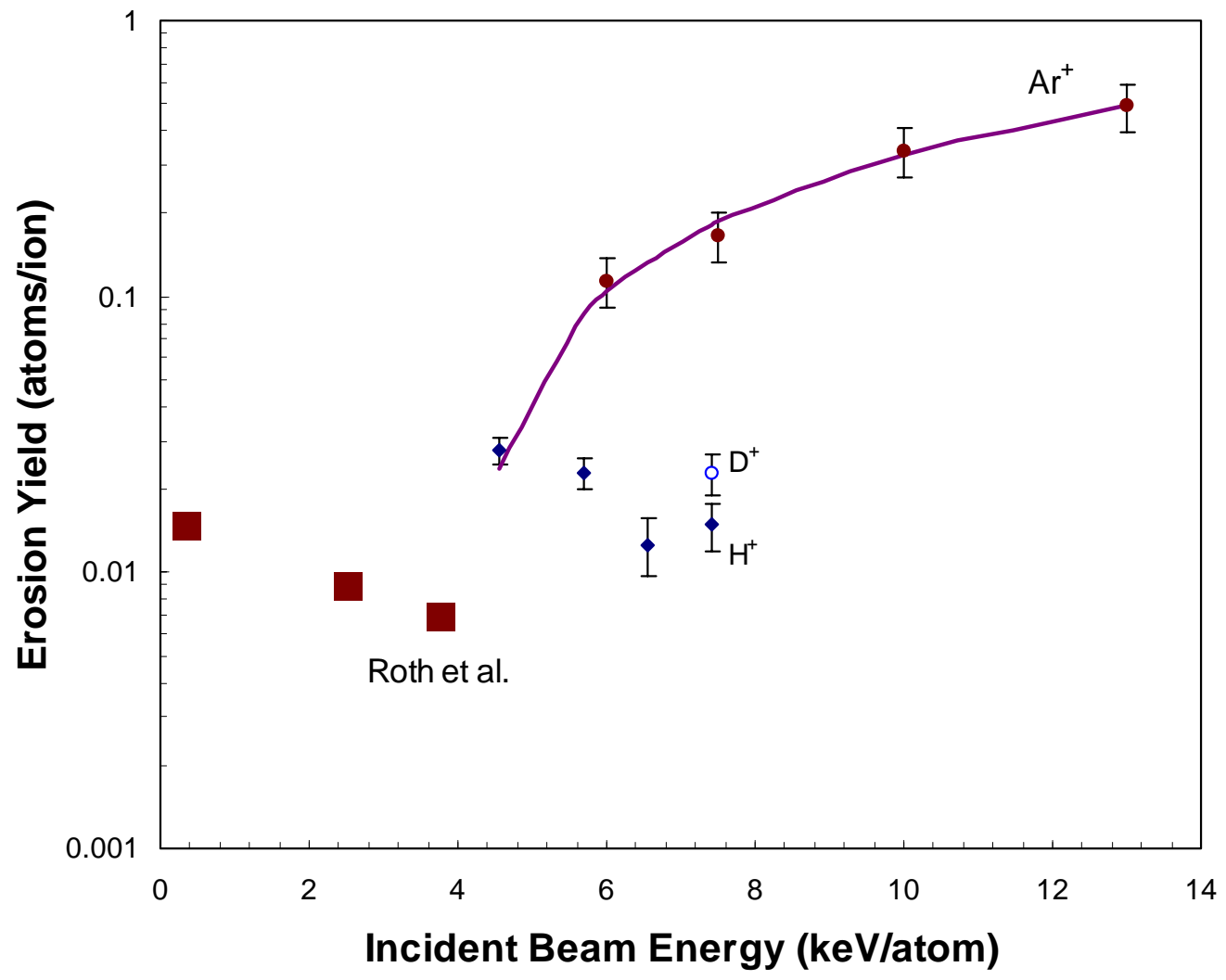

Figure 8. Erosion yields as a function of incident beam energy at $45^{\circ}$ incidence from Mohri et al. ${ }^{15}$ Also shown are normal-incidence data for $\mathrm{H}^{+}$bombardment of $\mathrm{SiC}$ from Roth et al. ${ }^{24}$ The line through the $\mathrm{Ar}^{+}$data is a least-squares linear fit.

If we multiply the $330-\mathrm{m}^{2}$ first wall area by an assumed particle flux of $10^{20} \mathrm{D} / \mathrm{T} / \mathrm{m}^{2} \mathrm{~s}$ (Table 1) for three years, we estimate the amount of $\mathrm{SiC}$ sputtered to be $5 \times 10^{4}$ moles. With a $\mathrm{H}: \mathrm{C}$ ratio of 0.01 (H:Si may be the same or slightly lower based on formation enthalpies) and assumed full deposition of the material in the vacuum vessel or in pumping ducts, the tritium inventory would be 50 moles, $150 \mathrm{~g}$, or $1.5 \mathrm{MCi}$, assuming all of the sputtered carbon and silicon combine in the ratio stated and that half of the codeposited species would be $\mathrm{D}$ and half $\mathrm{T}$. This is less than but comparable, considering the gross approximations made here, with the $580 \mathrm{~g}$ estimated by TMAP calculations in the next section to be resident in the first wall. The $150 \mathrm{~g}$ is about 0.2 percent of the tritium striking the first wall.

\section{Order of Magnitude Inventory}

An order of magnitude estimate of tritium inventory in the ARIES-AT may be drawn from the above considerations to be as shown in Table 2. It will be seen there that the preponderance of the nominal 760-g in-vessel inventory is in the $\mathrm{SiC}$ first wall structure, resident in the $\mathrm{SiC}$ itself. That grows nearly linearly in time and is limited by the low diffusivity of hydrogen 
species in the SiC. The next largest inventory is in the codeposited species that are assumed to plate out on the colder surfaces of the vacuum vessel or surrounding duct work. This estimate is highly uncertain because of the uncertainty in the tritium fraction in redeposited silicon and carbon, but also because of the uncertainty in the sputter yields for the plasma facing structures. Tritium in the divertor is least significant, but probably the best known.

Table 2. Order-of-magnitude estimate of tritium inventory in ARIES-AT after 3 years of operation. Figures could be low or high by a factor of 2 .

\begin{tabular}{|l|c|}
\hline Structure & Inventory (g) \\
\hline First Wall & 534 \\
\hline Divertor & 27 \\
\hline Codeposition Regions & 150 \\
\hline Total & 711 \\
\hline
\end{tabular}

It should be emphasized that these are single point values without the 2- or 3-dimensional nature of the various processes or states that influence tritium inventories taken into account.

\section{ACCIDENT CONSEQUENCES}

Suppose there were a loss-of-vacuum accident in which the vacuum chamber were to be penetrated with the associated development of an opening to the surroundings. The greatest immediate concern would be the levitation of the codeposited material and dust in the vessel and its potential for being carried to the surroundings by connective flows of air. The tritium inventory fraction so released would depend on the location of the break relative to the location where the codeposition took place and on the chemical state of the codeposited material. In some machines, the codeposited material became flaky and had a rather large dust component associated with it. In other machines, or in other parts of the same machines, there are areas where the codeposited film is tightly bonded to the first wall as a carbonaceous or polymer-like film. The former is subject to levitation, while the latter generally is not. Exposure to air, particularly if the coated walls are at elevated temperatures and/or the air is humid, can degrade the integrity of those coatings and allow the films to loosen and be eroded. That may be a concern over lengthy outages due to accidents.

Tritium in the tungsten divertor plates will come out at a high rate, even if the plates are at ambient temperature. Hence, any time the machine is non-operational, one may expect to see tritium coming from the divertor plates. This would constitute a continuing source if the machine were left open for any significant time with much of the inventory in the tungsten 
coming out in days to weeks, depending on the temperature. If the machine were not open but unpumped, the inventory of gaseous tritium in the vacuum chamber would climb.

It seems reasonable that with the bulk of the structure in the vacuum chamber being $\mathrm{SiC}$, there would not be a large amount of structural afterheat from radioactive decay, except possibly for the tungsten divertor plates. Hence, under accident conditions, it is likely that the temperatures of the $\mathrm{SiC}$ structures would not exceed their normal operating temperatures. The time it took to build the inventory in the walls would then be required to have the tritium escape, even if there were a readily absorbing medium at the SiC surface, such as moist air.

To evaluate that, we consider several accident scenarios using the TMAP4 code. First, the inventory is allowed to build for three years of operation under the worst-case conditions for the first wall, namely that there is effectively no reemission. Then it is assumed there is an accident, and the wall temperature is assumed to remain at one of several arbitrary temperatures for one year under the new worst-case scenario, that of essentially zero concentration at the first wall surface. Thus, the release is dominated by diffusivity in the SiC. Following the accident, the $\mathrm{SiC}$ structure is assumed to be held at 500,750 , and $1,000^{\circ} \mathrm{C}$. Release fractions after one year are $0.8,6.6$, and 39.7 percent, respectively. Results are shown in Figure 9

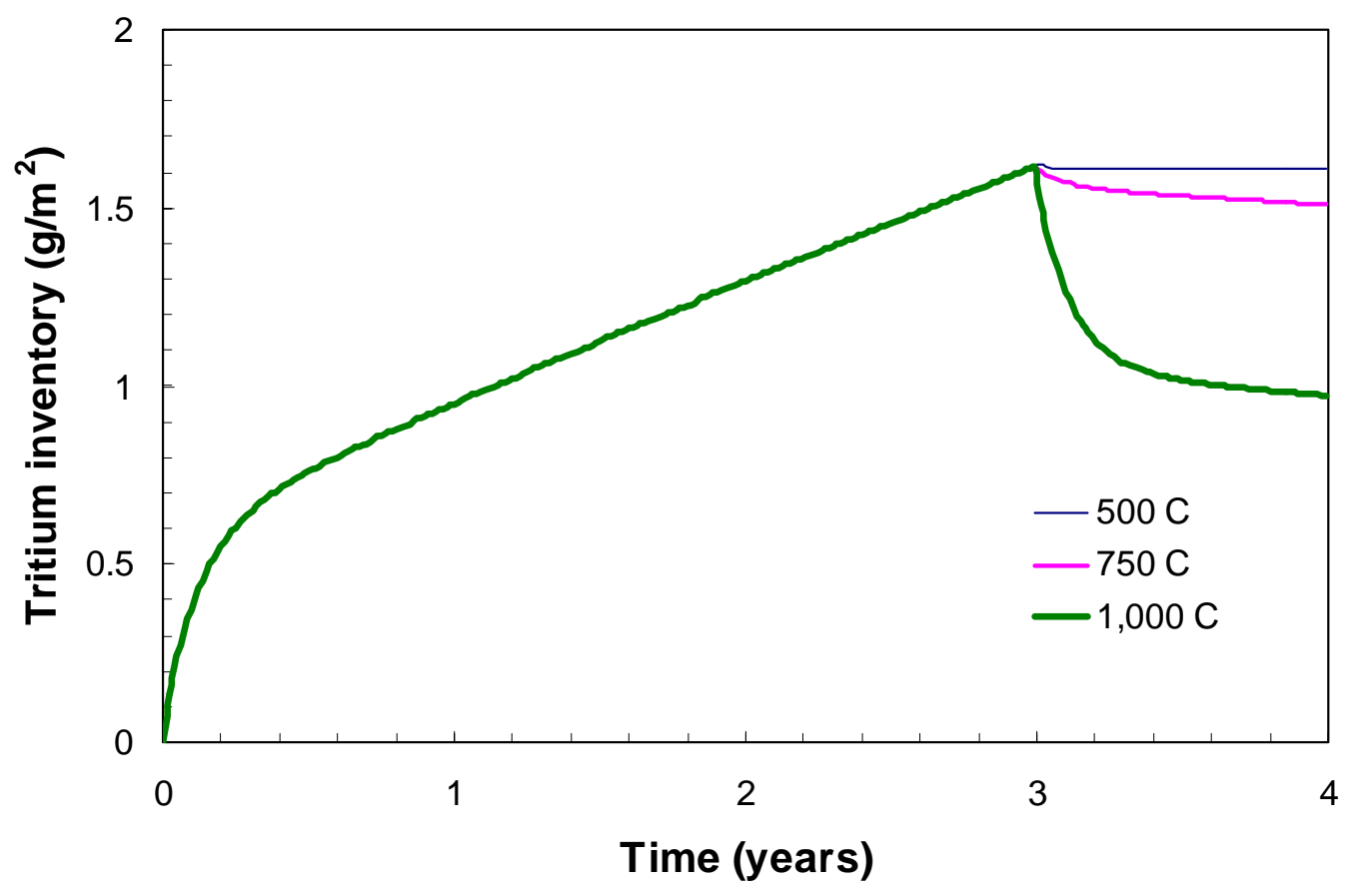

Figure 9. Release of tritium following three years of operation at $10^{21} \mathrm{DT} / \mathrm{m}^{2}$.s and assuming $\mathrm{SiC}$ structure is held at 500,750 , and $1,000^{\circ} \mathrm{C}$ following an accident. Release fractions after one year are $0.8,6.6$, and 39.7 percent, respectively. 
If there were to be a major thermal excursion that could raise the $\mathrm{SiC}$ temperature to 1,400 or $1,600^{\circ} \mathrm{C}$, there would probably be a significant change in the microstructure of the SiC. Bubbles would grow as swelling took place. There would be some connection of the bubbles with the surface through porosity that would develop, and the majority of the tritium inventory in the $\mathrm{SiC}$ would emerge in a short time.

Specifics of accidental releases must await better definition of conditions attendant to such accidents.

\section{REFERENCES}

1. A. R. Raffray and X. Wang, "Status ARIES-AT Blanket and Divertor Design," AIRES Project Meeting, University of California, San Diego, March 21, 2000.

2. A. Sayano et al., "Development of a reaction-sintered silicon carbide matrix composite," Journal of Nuclear Materials 271 \& 272 (1999) pp. 467-471.

3. K. Kawatsura et al., "Radiation-induced amorphization and recrystallization of $\alpha$-SiC single crystal," Journal of Nuclear Materials 271 \& 272 (1999) pp. 11-14.

4. J. A. Spitznagel et al., Nuclear Instruments and Methods B 1 (1986) p. 237.

5. H. Araki et al., "Effect of high temperature heat treatment in vacuum on microstructure and bending properties of $\mathrm{SiCf} / \mathrm{SiC}$ composites prepared by CVI," Journal of Nuclear Materials 258-263 (1998) pp. 1540-1545.

6. G. E. Youngblood et al., "Radiation response of SiC-based fibers," Journal of Nuclear Materials 258-263 (1998) pp. 1551-1556.

7 R. Scholz, "Light ion irradiation creep of SiC fibers in torsion," Journal of Nuclear Materials 258--263 (1998) pp. 1533-1539.

8 R. J. Price, "Properties of silicon carbide for nuclear fuel particle coatings," Nuclear Technology 35 (1977) pp. 320-336.

9. M. Saito et al., "Interface strength of $\mathrm{Sic} / \mathrm{SiC}$ composites with and without helium implantation using micro-indentation test," Journal of Nuclear Materials 258-263 (1998) pp. 1562-1566.

10. H. W. Scholz et al., "Swelling behaviour and TEM studies of SiCf/SiC composites after fusion relevant helium implantation," Journal of Nuclear Materials 258-263 (1998) pp. $1572-1576$. 
11. A. J. Frias Rebelo et al., "Comparison of the mechanical behaviour of $\mathrm{Sicf} / \mathrm{SiC}$ composites following neutron irradiation and helium implantation," Journal of Nuclear Materials 258-263 (1998) pp. 1582-1588.

12. D. J. Bacon et al., "The structure of graphite and silicon carbide resulting from helijmion bombardment," Journal of Nuclear Materails 103 \& 104 (1984) pp. 427-432.

13. W. P. West, General Atomics, private correspondence, June 7, 2000.

14. Y. Xu; L. Cheng; and L. Zhang, "Composition, microstructure, and thermal stability of silicon carbide chemical vapor deposited at low temperatures," Journal of Materials Processing Technology 14, Vol.101 (April 2000) pp.47-51.

15. M. Mohri et al., "Measurement of erosion yields for a $\mathrm{SiC}$ surface on $\mathrm{H}+, \mathrm{D}+$, and $\mathrm{Ar}+$ bombardment," Journal of Nuclear Materials 75 (1978) pp. 309-311.

16. G. Federici et al., "In-vessel tritium retention and removal in ITER," Journal of Nuclear Materials 266-269 (1999) pp. 14-29.

17. A. T. Peacock et al., "Dust and flakes in the JET MkIIa divertor, analysis and results," Journal of Nuclear Materials 266-269 (1999) pp. 423-428.

18. C. H. Skinner et al., "Modeling of tritium retention in TFTR," Journal of Nuclear Materials 266-269 (1999) pp. 940-946.

19. R. A. Causey, Sandia National Laboratories, private correspondence, May 11, 2000.

20. G. R. Longhurst, "Tritium Inventories and Permeation Rates for the ITER Breeding Blanket and Metal-coated Plasma-Facing Components for the Extend Performance Phase," ITER/US/97/TE/SA-22 Rev.1, September 24, 1997.

21. G. R. Longhurst, "Recalculation of Tritium Inventories in ITER Plasma-Facing Structures," ITER/US/98/TE/SA-9, May 11, 1998.

22. G. R. Longhurst et al., "Tritium saturation in plasma-facing materials surfaces," Journal of Nuclear Materials 258-263 (1998) pp. 640-644.

23. B. Doyle, W. R. Wampler, and D. K. Brice., "Temperature dependence of H saturation and isotope exchange," Journal of Nuclear Materials 103-104 (1981) pp. 513-518.

24. J. Roth et al., "Physical and chemical sputtering of graphite and $\mathrm{SiC}$ by hydrogen and helilum in the energy range of 600 to $7500 \mathrm{eV}$," Journal of Nuclear Materials 63 (1976) pp. 222-229. 


\section{APPENDIX A: TMAP INPUT FILES AND RESULTS}

\section{Reference Case}

Input file and inventory buildup history for zero concentration boundary conditions, where $\mathrm{SiC}$ is implanted at $100 \mathrm{eV}$, normal incidence at a flux density of $1.0 \times 10^{21} \mathrm{D} / \mathrm{m}^{2}-\mathrm{s}$. Results are generally representative of a D/T mixture. After nominally 149 weeks, the inventory was $7 \times 10^{23} \mathrm{D} / \mathrm{m}^{2}$. If half of that inventory were tritium, that would correspond to $1.75 \mathrm{~g} / \mathrm{m}^{2}$ of surface area. Increasing the implantation flux by a factor of ten increases the inventory by that same factor of ten.

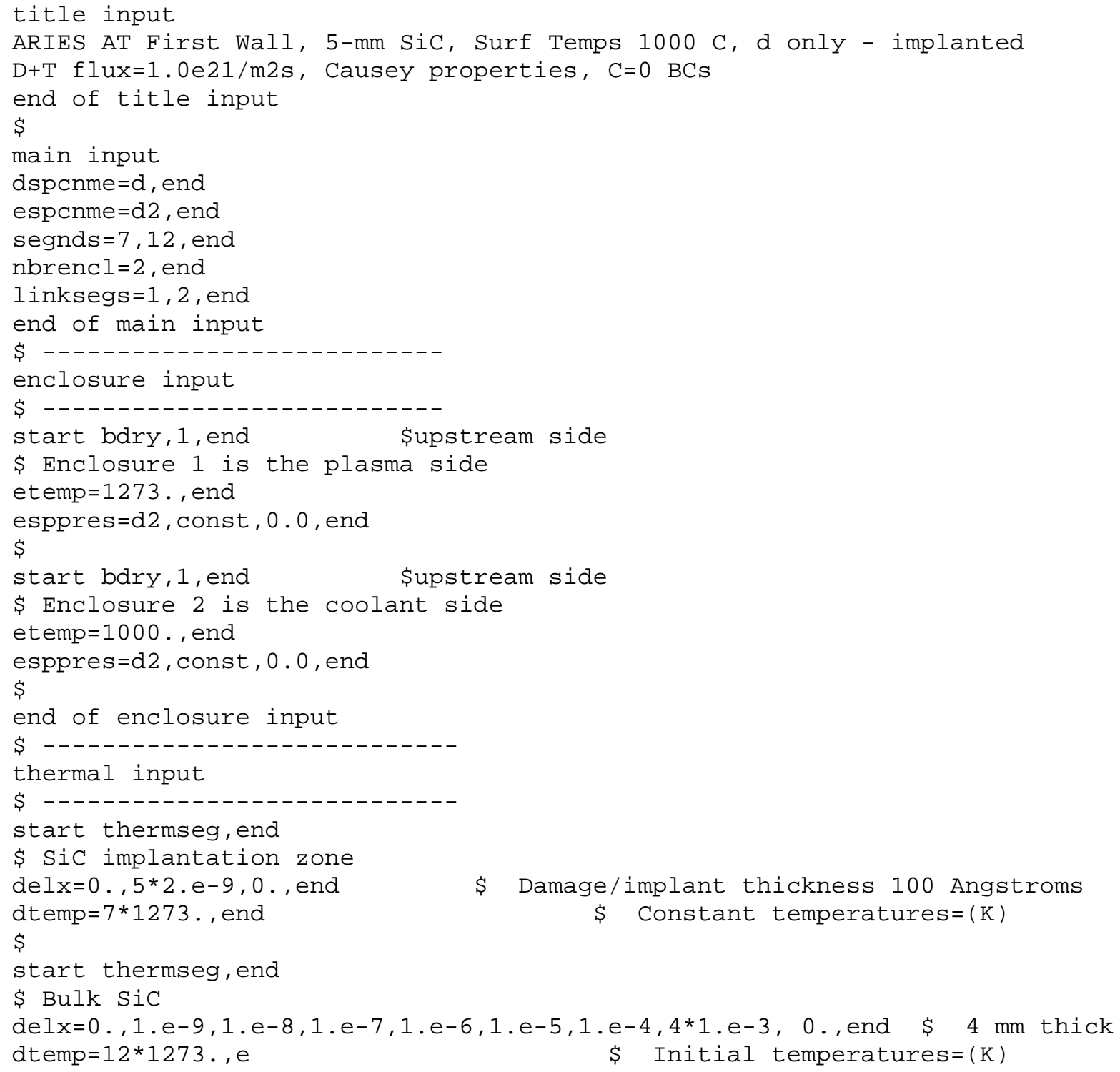




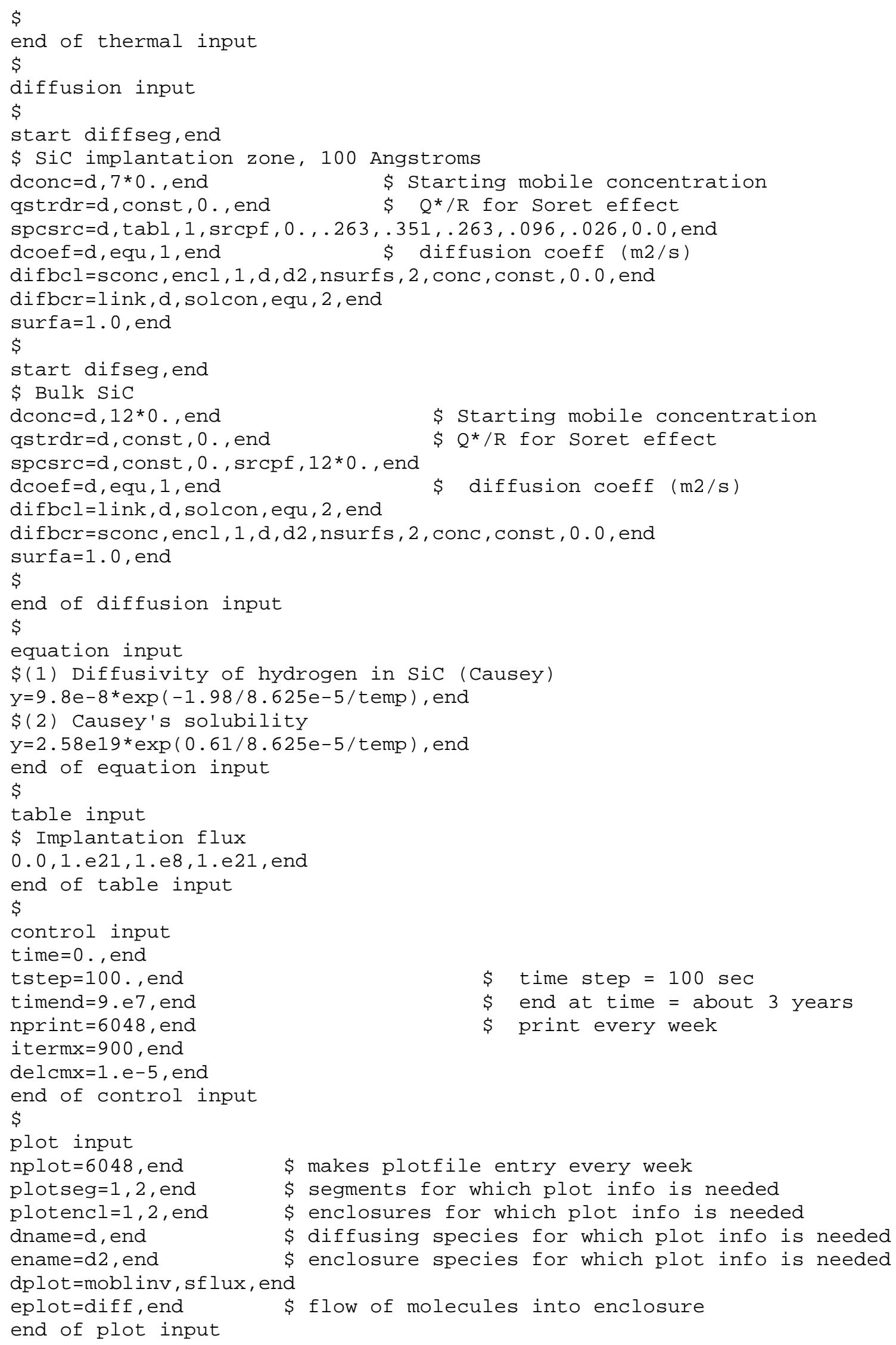


$\$$

end of data

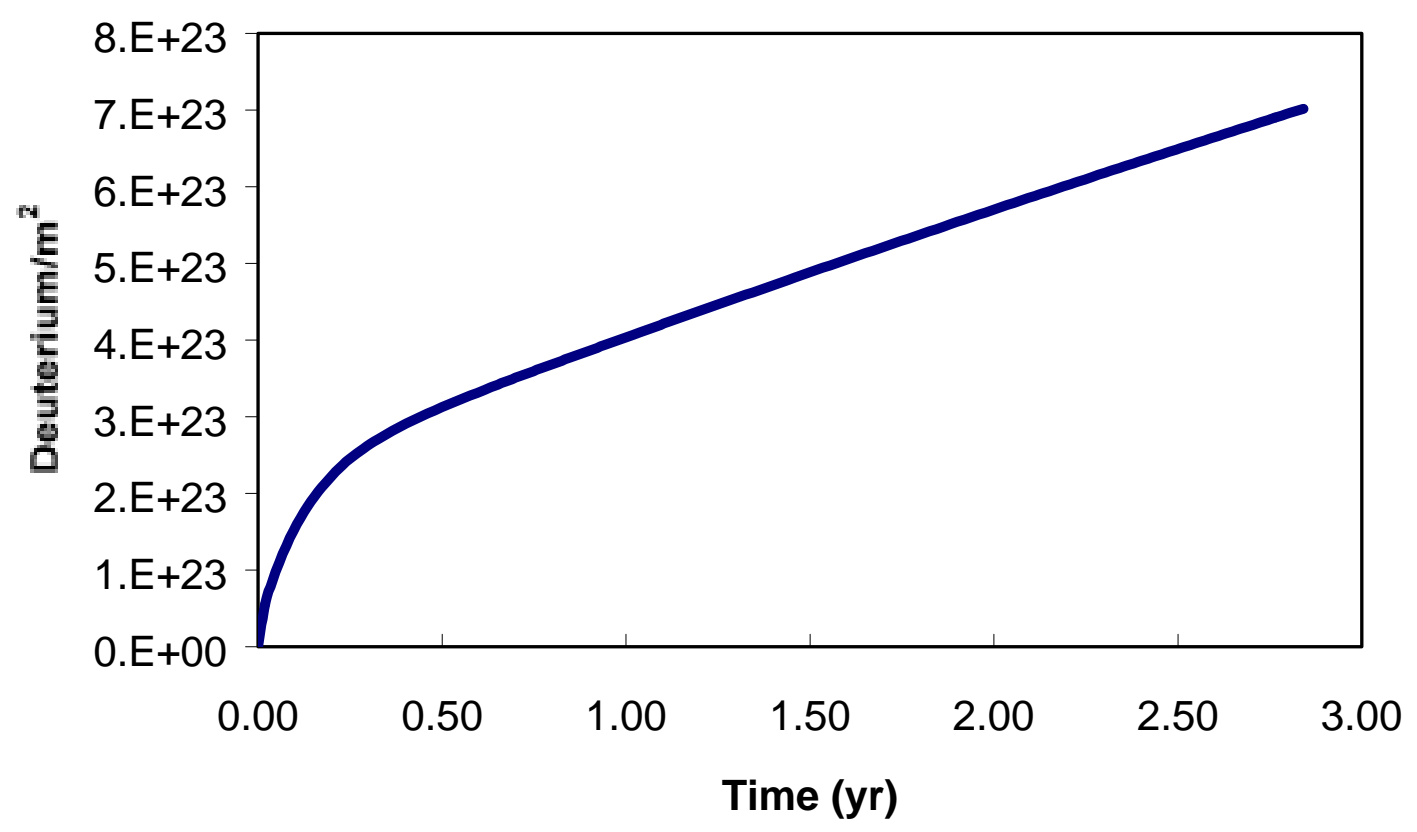

Figure A-1. Calculated inventory buildup history for deuterium implanted at $100 \mathrm{eV}$ with zero concentration boundary conditions. Assymptotic inventory limit is $4.96 \times 10^{24}\left(\mathrm{D} / \mathrm{m}^{2}\right)$

\section{With Temperature Gradient and Trapping}

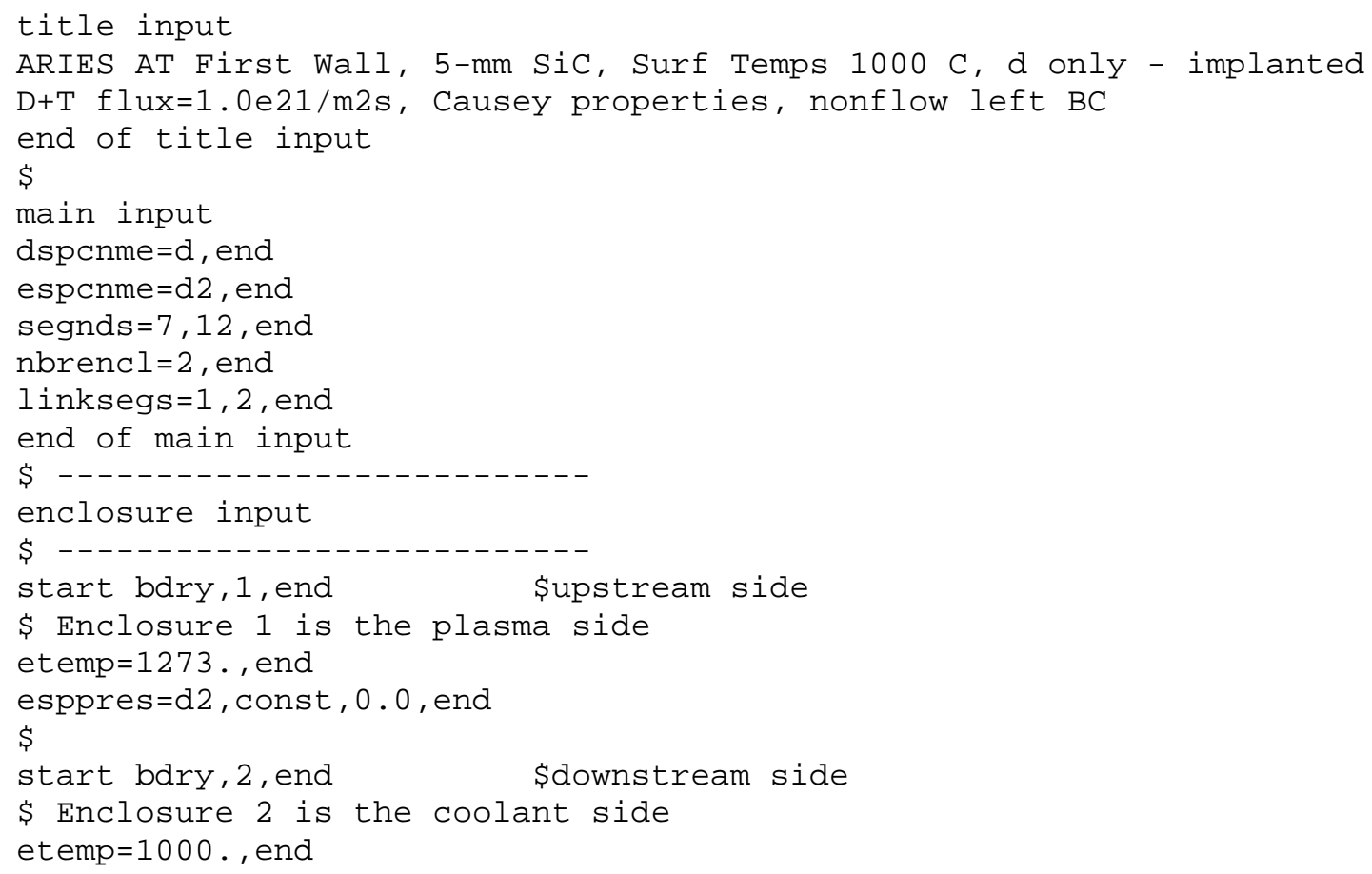




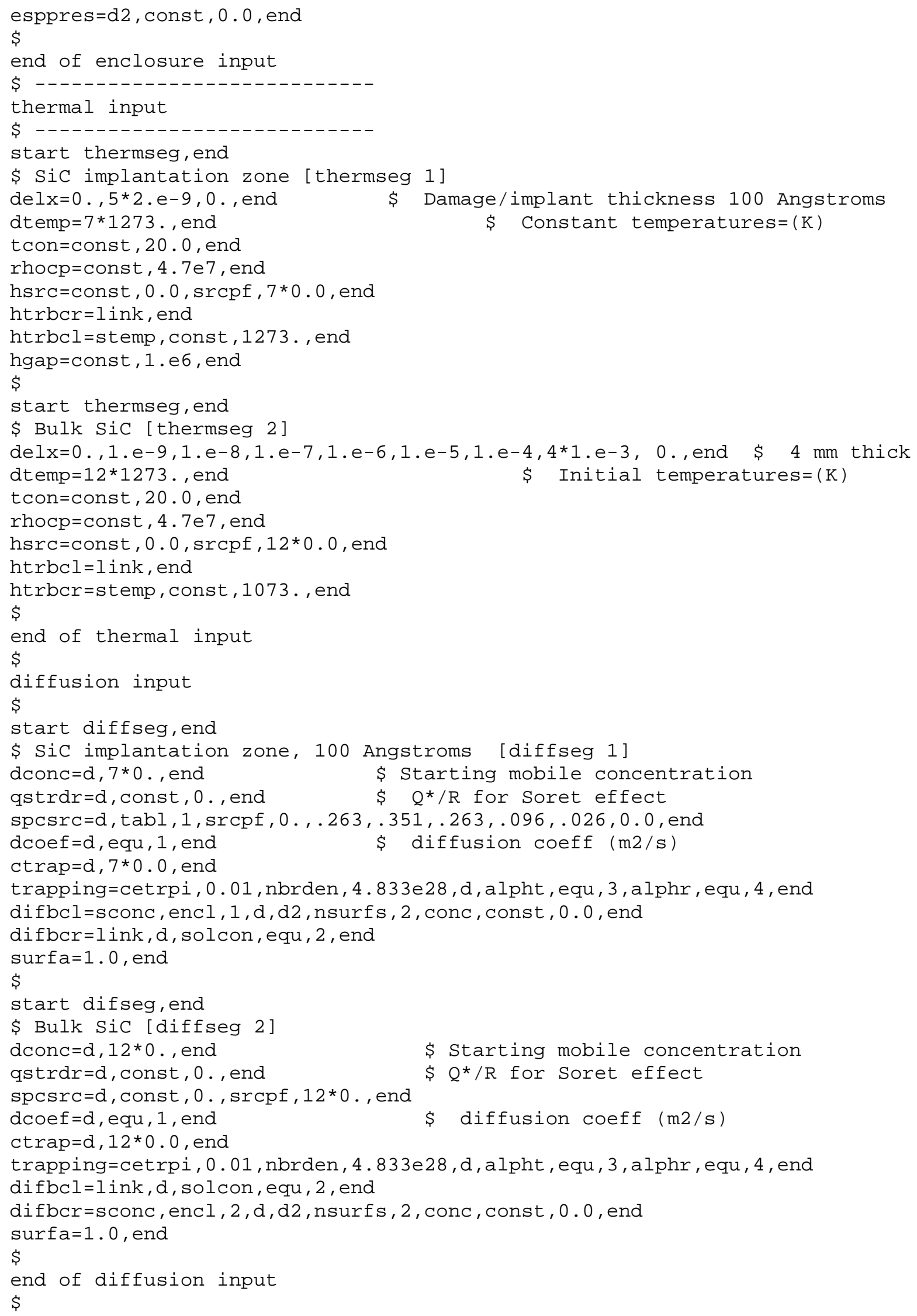




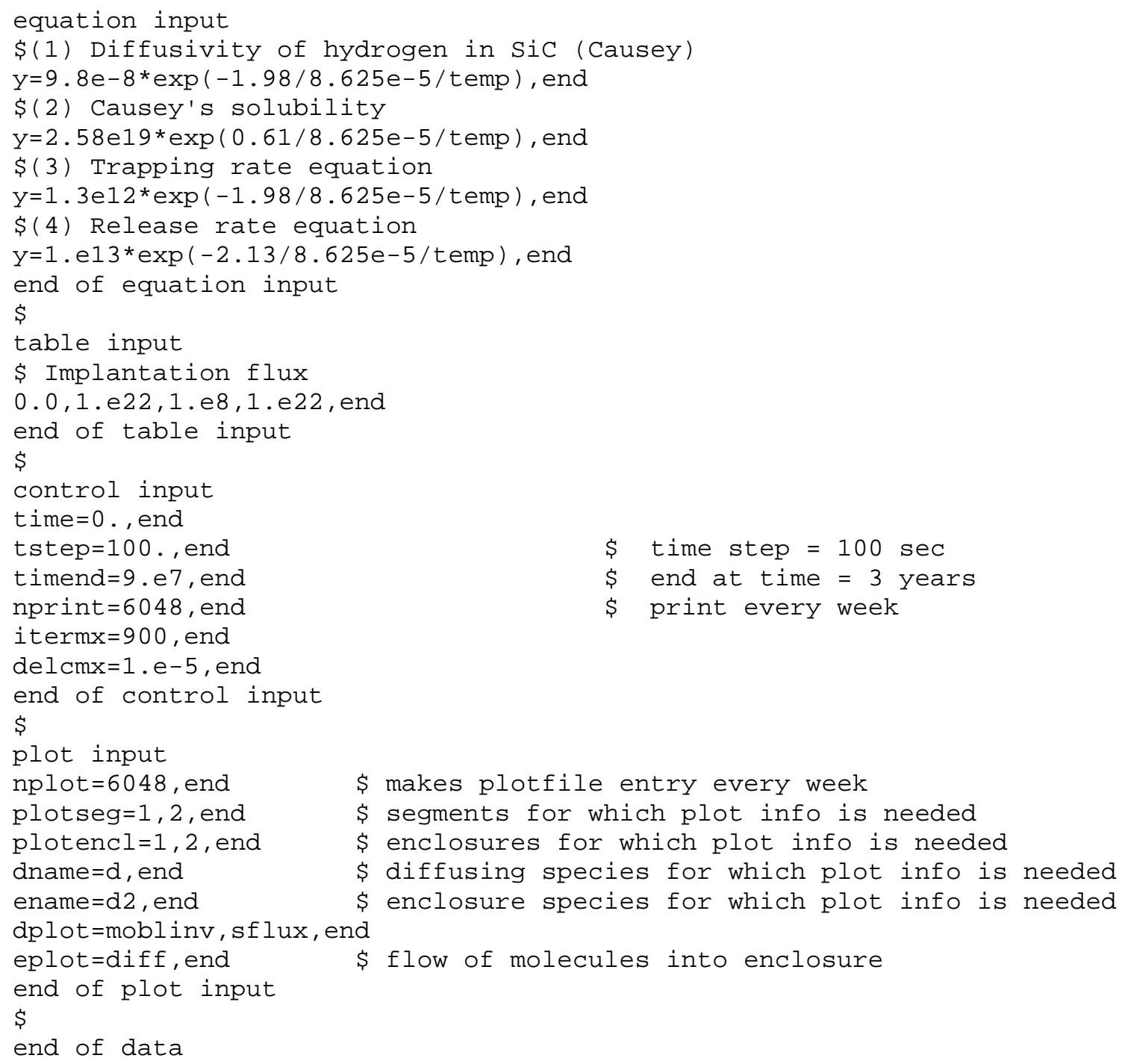




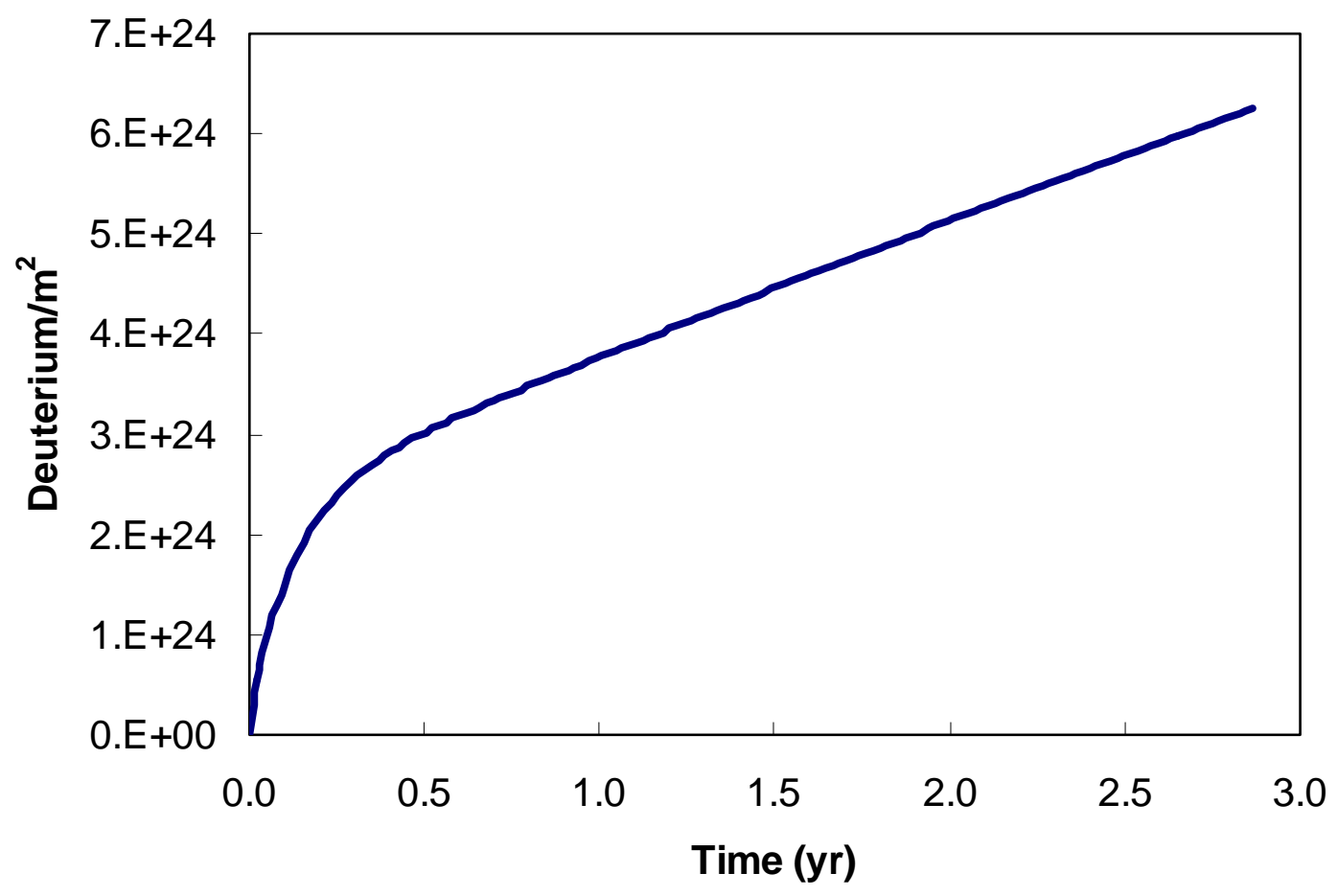

Figure A-2. Calculated inventory buildup history for deuterium implanted at $100 \mathrm{eV}$ with zero concentration boundary conditions, but modified with thermal gradient and trapping. Traps with $2.1-\mathrm{eV}$ trap energy and 0.01 atom fraction added 1 percent to the inventory. 